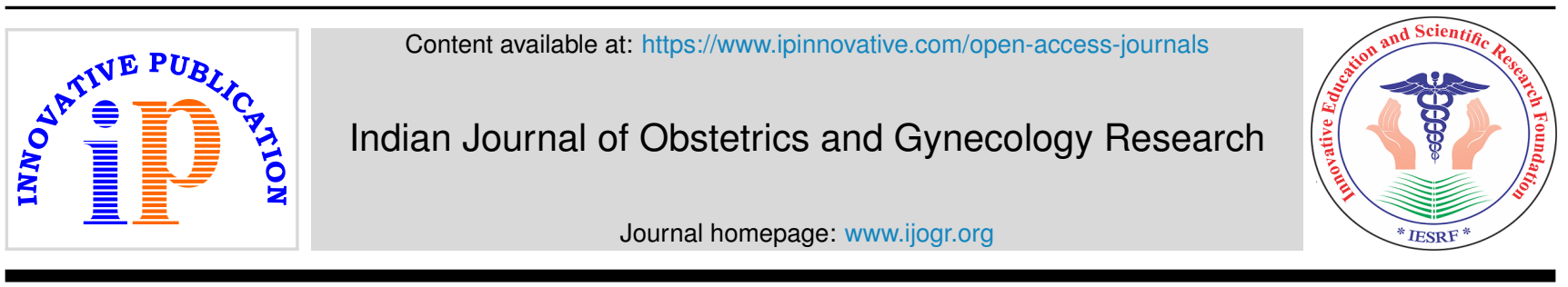

Original Research Article

\title{
COVID 19 in pregnancy; obstetrical and neonatal outcomes: A retrospective comparative study
}

\author{
Vikas Yadav $^{1}$,*, Neerja Goel ${ }^{1}$, Naima Afreen ${ }^{1}$, Nimmi Chutani ${ }^{1}$, Shelly Agarwal ${ }^{1}$, \\ Archana Mehta ${ }^{1}$ \\ ${ }^{1}$ Dept. of Obstetrics and Gynecology, SMS\&R, Sharda Hospital, Greater Noida, Uttar Pradesh, India
}

\section{A R T I C L E I N F O}

\section{Article history:}

Received 24-07-2020

Accepted 29-07-2020

Available online 07-12-2020

Keywords:

COVID positive

Pregnant

Preterm delivery

Perinatal outcome

\begin{abstract}
A B S T R A C T
Background: COVID 19 is a new pandemic affecting human life globally. Complexity in management is because little is known about effect of COVID 19, particularly its effect on pregnant women and infants. Pregnant women with comorbidities are more vulnerable to severe effects of COVID 19 infection. The aim of this retrospective study is to review the perinatal outcome in pregnant women affected by COVID 19. Materials and Methods: This was a single centre retrospective comparative study performed at COVID referral centre. The study was conducted in 4 months duration in patients diagnosed COVID 19 positive and were compared with all pregnant women who were tested COVID negative and delivered during the same time frame. Data collected from individual case records included age, parity and complications in the antenatal, intrapartum and postpartum periods and also neonatal outcome.

Results: Out of 28 patients there were 6 (21.4\%) patients who presented with fever, 4 (14.3\%) patients presented with cough, $2(7.14 \%)$ patients presented with shortness of breath, $14(50 \%)$ were asymptomatic who were incidentally diagnosed on COVID testing based on routine hospital testing policy. Mean age was $25.35 \pm 3.31$ years in COVID positive patients and was comparable to COVID negative patients who had mean age of $26.16 \pm 3.32$ years. Parity was comparable in two groups. $8(28.5 \%)$ out of 28 had preterm delivery as compared to $13(11.6 \%)$ out of 112 in COVID negative group, $p$ value was significant $(\mathrm{p}=0.0245$. In COVID positive group 18 (64.3\%) out of 28 had c-section, whereas $40(35.7 \%)$ out of 112 underwent cesarean section $(\mathrm{p}=0.006)$.

Conclusion: There has been increase in preterm delivery in COVID positive pregnant women. This study emphasize on the need for regular antenatal and medical follow up and good perinatal care for COVID positive mothers.

(C) This is an open access article distributed under the terms of the Creative Commons Attribution License (https://creativecommons.org/licenses/by/4.0/) which permits unrestricted use, distribution, and reproduction in any medium, provided the original author and source are credited.
\end{abstract}

\section{Introduction}

WHO on February 11, 2020 announced name for the new coronavirus disease: COVID 19. This started the emergence of a new pandemic affecting human life globally. Number of patients affected globally and death rate in 215 countries by July 2020 is $1,37,06,050$ and 5,87,144 respectively. ${ }^{1}$ Many obstetric associations have responded with series of guiding documents to navigate through this unknown territory. Much of the data available to obstetricians is

\footnotetext{
* Corresponding author.

E-mail address: vikiyadav1789@gmail.com (V. Yadav).
}

in the form of case studies, case series and observational studies that too mainly from china. These are reported in Chinese language resulting in gap of evidence. ${ }^{2}$ Complexity in management is because little is known about effect of COVID 19, particularly its effect on pregnant women and infants. $^{3}$

The predominant features of COVID 19 in pregnancy are cough, fever, dyspepsia, shortness of breath that can mimick physiological dyspnea due to increased maternal oxygen consumption because of physiological anemia and increased metabolism in pregnancy. ${ }^{4}$ In cases of severe illness including pneumonia with or without acute 
respiratory distress, multi organ dysfunction, it may require immediate advanced critical care support. ${ }^{5}$ Pregnant women with Gestational diabetes mellitus (GDM) or overt DM, hypertension, asthma, HIV, chronic liver disease, chronic kidney disease, blood dyscrasias and those with organ transplant and malignancies have been identified as been more vulnerable to severe effects of COVID 19 infection. ${ }^{6}$

Real time reverse transcriptase -polymerase chain reaction assay (Rt- PCR) from respiratory specimen is the current gold standard for detecting SARS $-\mathrm{Cov}-2 .^{7}$ When HRCT is required for further investigations, it should not be delayed in pregnant women. The US Centre for Disease Control (CDC) has stated that pregnant women seem to have the same risk as adults who are not pregnant. ${ }^{8}$ Whereas some studies even suggest that due to relative immunosuppression in pregnancy, intense inflammation response evoked by COVID 19 may not develop into severe respiratory symptoms. ${ }^{9}$

To facilitate the understanding of pregnancy in COVID 19 , the aim of this retrospective study is to review the perinatal outcome in pregnant women affected by COVID 19 , its psychological impact and its wider implications on healthcare services.

\section{Materials and Methods}

This was a single centre, retrospective comparative study performed in Sharda School of Medical Sciences and Research, Greater Noida, UP. It is the only dedicated Level 3 (L3) Hospital in district catering to critical patients with morbidity.

We included all COVID Positive pregnant women who came to our centre for quarantine or management as per governments protocol in 4 months duration between $23 / 3 / 2020$ till 23/07/2020. All the patients were diagnosed COVID 19 positive based on positive RT-PCR report from nasopharyngeal and oral swabs. ${ }^{10}$ Women were compared with controls in the ratio of four controls for each case. Controls were all pregnant women who were tested COVID negative and delivered during the same time frame.

Data collected from individual case records included age, parity and complications in the antenatal, intrapartum and postpartum periods. The mean birth weights of infant and the frequency of small for gestation age (weight less than 10th centile for that gestation), neonatal depression (APGAR score of 6 or less at one minute after birth) and still births were used for perinatal outcome. Data also included time from onset of symptom to hospital admission, symptoms, severity of COVID 19 based on requirement of oxygen support, vitals on admission, lab tests, radiological imaging findings, treatment regimen received (antivirals, HCQ, ivermectin, corticosteroids), length of stay at hospital. These were compared between two groups.

As this was observational retrospective study, data was taken from hospital records with approval of hospitals medical record department and institute medical ethics committee. The medical records of the included patients were reviewed.

\subsection{Statistical analysis}

The relevant data were collected, summarized, tabulated, and analyzed using Statistical Package for the Social Sciences version 19 software (IBM, Armonk, NY, USA). $\mathrm{P}<0.05$ was considered to be statistically significant at a 95\% confidence interval. The chi-square (c2), Yates' correction of c2, and Fisher's exact tests were used to compare proportions. Analysis of variance (or F test) was used to compare the means between more than two groups.

\section{Results}

During the period of study of 4 months between $23 / 03 / 2020$ to $23 / 07 / 2020$, twenty-eight (28) pregnant women diagnosed COVID positive delivered in obstetrical unit of our department and were compared with 112 COVID negative pregnant women.

\subsection{Clinical presentation in COVID 19 pregnant}

The clinical presentation in COVID 19 pregnant patients are summarized in detail in Table 1 . Out of 28 patients there were $6(21.4 \%)$ patients who presented with fever, $4(14.3 \%)$ patients presented with cough, $2(7.14 \%)$ patients presented with shortness of breath, $2(7.14 \%)$ patients presented with diarrhea and 4 (14.3\%) patients had vague symptoms like loss of appétit, headache, fatigue, these symptoms were mimicking the physiological changes of pregnancy. Out of 28 patients $14(50 \%)$ were asymptomatic who were incidentally diagnosed on COVID testing based on routine hospital testing policy.

\subsection{Baseline characteristics comparison between two groups}

When comparing the baseline characteristics between COVID positive and COVID negative patients, mean age was $25.35 \pm 3.31$ years in COVID positive patients and was comparable to COVID negative patients who had mean age of $26.16 \pm 3.32$ years. Parity was comparable in two groups. Associated medical comorbidities like hypertension, diabetes, hepatitis and hypothyroidism were comparable between two groups and there was no statistically significant difference between two groups. Comparing obstetrical complications out of 28 COVID patients there were $8(28.56 \%)$ pregnant women with $\mathrm{hb}<10$ as compared to $16(14.28 \%)$ out of 112 in COVID negative patients $(\mathrm{P}=0.0728$ not significant). There were $4(14.28 \%)$ patients with GDM in COVID positive group as compared to $9(8.03 \%)$ in COVID negative group $(\mathrm{P}=0.308$ not significant). Other obstetric complications 
like Pregnancy induced hypertension (PIH), Intrahepatic cholestasis (ICP) and Antepartum hemorrhage (APH) were comparable in two groups and were statistically non significant $(\mathrm{p}>0.05)$. Baseline characteristics are summarized in Table 3.

\subsection{Outcome in COVID 19 positive pregnant women}

All COVID positive pregnant women were either asymptomatic or in symptomatically mild category they were started prophylactically on multivitamins in addition to iron and calcium prophylaxis. Patients with milder symptoms were also started on prophylactic hydroxychloroquine, ivermectin or tamiflu. Out of 28 patients $8(28.5 \%)$ received either azithromycin or cephalosporins to counter superaded bacterial infections. $2(7.14 \%)$ out of 28 received HCQ and ivermectin each. Average length of hospital stay was $10.18 \pm 1.69$ days. There was no patient needing oxygen support. None of the patient deteriorated to ventilator support. There was no maternal mortality in COVID positive pregnant women. It is summarized in Table 4.

\subsection{Comparison of obstetrical outcome}

Obstetrical outcomes were noted between COVID positive pregnant women and COVID negative pregnant women and compared between the two groups. Mean gestation age at delivery for COVID positive group was $36.8 \pm 2.49$ weeks as compared to $37.95 \pm 2.31$ weeks in COVID negative group, it was statistically significant $(\mathrm{p}=0.023)$. Out of 28 pregnant women in COVID positive group $8(28.5 \%)$ had preterm delivery as compared to $13(11.6 \%)$ out of 112 in COVID negative group, $\mathrm{p}$ value was significant $(\mathrm{p}=0.0245$. In COVID positive group $18(64.3 \%)$ out of 28 had csection and $10(35.7 \%)$ had delivered vaginally with most common reason of cesarean section being patient choice due to apprehension of fetal risk of infection, whereas $40(35.7 \%)$ out of 112 underwent cesarean section and $72(64.3 \%)$ delivered vaginally with most common reason being fetal distress. On comparing mode of delivery it was statistically significant $(\mathrm{p}=0.006)$. Mean birthweight in COVID positive group was $2511.93 \pm 692.23$ grams as compared to $2674.98 \pm 543.75$ grams in COVID negative group and it was not statistically significant $(\mathrm{p}=0.1861)$ It is summarized in Table 5.

\subsection{Comparison of neonatal outcome}

Comparing the neonatal outcome between COVID positive pregnant women and COVID negative pregnant women. All neonates of COVID positive mother had COVID sampling done within $6 \mathrm{hrs}$ of birth and report came negative. Small for gestational age babies were $8(28.5 \%)$ out of 28 COVID positive pregnant women as compared to $13(11.6 \%)$ out of 112 in COVID negative group, p value was significant $(\mathrm{p}=0.0245)$. There were $2(7.14 \%)$ babies with APGAR score $<6$ at 1 - minute out of 28 in COVID positive group as compared to $3(2.67 \%)$ out of 112 in COVID negative group, $\mathrm{p}$ value was not significant $(\mathrm{p}=0.2549)$. Out of 28 babies $4(14.28 \%)$ had NICU stay of more than 3 days as compared to $8(7.14 \%)$ out of 112 in COVID negative group, $\mathrm{p}$ value was not significant $(\mathrm{p}=0.2272)$. Neonatal complications like respiratory distress, neonatal jaundice were noted in $6(21.4 \%)$ in COVID positive group as compared to 8 (7.14\%) out of 112 in COVID negative group, $\mathrm{p}$ value was not significant $(\mathrm{p}=0.1297)$. There was one early neonatal death in COVID positive group as compared to $1(0.89 \%)$ out of 112 in COVID negative group $(\mathrm{p}=0.858$ non significant). Baby was delivered preterm at 36 weeks gestation and at birth baby had depressed APGAR of 4 at 1 minute following which baby was resuscitated but baby had severe respiratory distress and went into shock and was kept on inotropes and ventilator support but 24 hours after birth baby had cardiorespiratory failure and could not be revived. It is summarized in Table 5.

\section{Discussion}

FIGO currently recommend that during the course of pandemic, antenatal women should limit the number of antenatal visits and should observe strict self isolation and good hand hygiene. ${ }^{11}$

Similar to non pregnant patients the predominant features of COVID 19 are fever, cough, dypnoea and lymphopenia. Similar observations were made by various clinicians, ${ }^{12}$ summarized in Table 2.

Currently evidence is lacking that suggest terratogenicity with COVID 19. Also there has been no increased risk of miscarriage or early pregnancy loss. Till now evidence of vertical transmission is related to meager one or two case reports. ${ }^{13}$ By and large there is lack of data on vertical transmission. ${ }^{14}$ In present study there was no COVID positive neonate.

There are emerging reports of venous and arterial thromboembolism in patients with COVID 19. ${ }^{15}$ Anticoagulant treatment with Low molecular weight heparin (LMWH) has been associated with improved prognosis. ${ }^{16}$ In present study one patient with known antiphospholipid antibody syndrome was continued on injection enoxaparin till $24 \mathrm{hrs}$ before c-section and was restarted 12 hours postpartum and continued for 6 weeks. Royal college of Obstetrics and Gynecology (RCOG) recommends thromboprophylaxis for all pregnant women admitted with COVID 19 infection. ${ }^{17}$

At present there is insufficient evidence to determine any correlation between spontaneous preterm labor and COVID 19 infection in pregnancy. ${ }^{18}$ In our study $8(28.5 \%)$ out of 28 COVID positive pregnant women had preterm delivery as compared to $13(11.6 \%)$ out of 112 in COVID negative group, $p$ value was significant $(\mathrm{p}=0.0245)$. A systematic 
Table 1: Most common symptoms observed in pregnant women with COVID 19

\begin{tabular}{lc}
\hline Symptoms & Number of Patients $(\mathbf{N}=\mathbf{2 8})($ percentage \%) \\
Fever & $6(21.4)$ \\
Cough & $4(14.3)$ \\
Shortness of breath & $2(7.14)$ \\
Diarrhoea & $2(7.14)$ \\
Leucocytosis & $2(7.14)$ \\
Others = nasal congestion, anosmia, headache, loss of & $4(14.3)$ \\
appetite & $14(50)$ \\
None & $14(5)$ \\
\hline
\end{tabular}

\#- some patients have combination of symptoms

Table 2: An overview of most common symptoms in pregnancy observed by various clinicians in conformed COVID 19

\begin{tabular}{lcccc}
\hline Symptoms & Dashraath et al (\%) & Yu et al (\%) & Chen et al (\%) & Elshafey et al (\%) \\
Fever & 84 & 86 & 75 & 67.3 \\
Cough & 28 & 14 & 13 & 7 \\
Dyspnoea & 18 & 14 & 7 & 7.3 \\
Diarrhoea & & & 44 & 14 \\
Lymphopenia & 38 & & 6 & $<3 \%$ \\
Leucocytosis & 22 & & \\
Other: Nasal congestion, rash, & & & \\
sputum, headache, loss of & & & \\
appetite & & & \\
\hline
\end{tabular}

Table 3: Comparison of baseline characteristics between COVID positive and COVID negative pregnant women

\begin{tabular}{|c|c|c|c|}
\hline Baseline Characteristics & $\begin{array}{l}\text { COVID Positive } \\
\text { Pregnant Women } \\
(\mathrm{N}=28)(\%)\end{array}$ & $\begin{array}{l}\text { COVID Negative Pregnant } \\
\text { Women }(\mathrm{N}=112)(\%)\end{array}$ & P Value \\
\hline Age (Mean Age \pm SD) & $25.35 \pm 3.31$ & $26.16 \pm 3.32$ & $P=0.2525$ \\
\hline \multicolumn{4}{|l|}{ Parity } \\
\hline Primi & $8(28.5)$ & $34(30.35)$ & \\
\hline Multi & $20(71.5)$ & $78(69.64)$ & $\mathrm{P}=0.8536$ \\
\hline $\begin{array}{l}\text { Gestational Age at Delivery } \\
(\text { Mean } \pm \text { SD })\end{array}$ & $36.8 \pm 2.49$ & $37.95 \pm 2.31$ & $\mathrm{P}=0.0230$ Significant \\
\hline \multicolumn{4}{|l|}{$\begin{array}{l}\text { Associated medical } \\
\text { comorbidities }\end{array}$} \\
\hline Hypertension & $2(7.14)$ & $5(4.46)$ & $\mathrm{P}=0.5607$ \\
\hline Diabetes & $1(3.5)$ & $4(3.57)$ & $\mathrm{P}=0.988$ \\
\hline Hepatitis & 0 & $2(1.78)$ & $\mathrm{P}=0.4763$ \\
\hline Hypothyroidism & $4(14.28)$ & $9(8.03)$ & $\mathrm{P}=0.3098$ \\
\hline \multicolumn{4}{|l|}{ Obstetric complications } \\
\hline $\mathrm{HB}<10$ & $8(28.56)$ & $16(14.28)$ & $\mathrm{P}=0.0728$ \\
\hline GDM & $4(14.28)$ & $9(8.03)$ & $\mathrm{P}=0.3081$ \\
\hline $\mathrm{PIH}$ & $3(10.7)$ & $8(7.14)$ & $\mathrm{P}=0.5298$ \\
\hline $\mathrm{ICP}$ & $3(10.7)$ & $14(12.5)$ & $\mathrm{P}=0.7958$ \\
\hline APH & $2(7.14)$ & $4(3.57)$ & $\mathrm{P}=0.4056$ \\
\hline
\end{tabular}

review of 33 studies by Gillian A Ryan et al described the outcome of 385 pregnant women with COVID 19 with period of gestation ranging from 30 to 41 weeks, a preterm birth rate of $15.2 \%$ was noted. ${ }^{19}$

With the recent data suggesting role of dexamethasone in moderate to severe infected cases, giving steroid coverage for fetal lung maturity in preterm fetuses should be actively considered. ${ }^{20}$ In present study $8(28.5 \%)$ of 28 COVID positive patients who were delivered preterm 4 (14.2\%) received full course of 4 doses of intramuscular injection of dexamethasone and had positive neonatal effect in terms of lung maturity.

Cesarean section rates for women with confirmed COVID 19 infection ranges from 40 to as high as $90 \% .{ }^{21}$ In a review by Di Mascio the cesarean section rate was higher than $90 \%$ and most of these c-sections were performed in maternal interest due to concern of fetal infection and worsening of maternal respiratory function. In current study 
Table 4: Outcome in COVID 19 positive pregnant women

\section{Outcome in COVID 19 Patients}

1. Treatment received by pregnant women:

Tamiflu

Antibiotic (Azithro/Cephalosporins)

HCQ

Ivermectin

2. Length of hospital stay

3. Need for oxygen support

4. Patient deteriorated to ventilatory support

5. Number of deaths
Number of Patients $($ Total $=28)(\mathbf{N})$

8 (28.5)

$2(7.14)$

2 (7.14)

$10.18 \pm 1.69$

0

0

0

Table 5: Comparison of obstetrical and neonatal outcome between COVID positive and negative pregnant women

\begin{tabular}{lccc}
\hline Outcome & $\begin{array}{c}\text { COVID Positive Pregnant } \\
\text { Women }(\mathbf{N}=\mathbf{2 8})(\boldsymbol{\%})\end{array}$ & $\begin{array}{c}\text { COVID Negative Pregnant } \\
\text { Women (N=112) }\end{array}$ & P value \\
$\begin{array}{l}\text { Obstetric Outcome } \\
\text { A. Gestational Age on Delivery (in }\end{array}$ & $36.8 \pm 2.49$ & $37.95 \pm 2.31$ & $\mathrm{P}=0.023$ Significant \\
$\begin{array}{l}\text { B. Number of Preterm Delivered } \\
\text { C. Mean Birth Weight (in grams) }\end{array}$ & $8(28.5)$ & $13(11.6)$ & $\mathrm{p}=0.0245$ Significant \\
D. Mode of Delivery & $2511.93 \pm 692.23$ & $2674.98 \pm 543.75$ & $\mathrm{p}=0.1861$ \\
- Vaginal Delivery & $10(35.7)$ & $72(64.3)$ & $\mathrm{p}=0.006$ Significant \\
- Section & $18(64.3)$ & $40(35.7)$ & $\mathrm{p}=0.0245$ Significant \\
Neonatal Outcome & $8(28.5)$ & $13(11.6)$ & $\mathrm{p}=0.2549$ \\
A. Small for Gestation Babies & $2(7.14)$ & $3(2.67)$ & $\mathrm{p}=0.2272$ \\
$\begin{array}{l}\text { B. Number of Babies with Apgar } \\
\text { Score<6 AT 1- Minute }\end{array}$ & $4(14.28)$ & $8(7.14)$ & $\mathrm{p}=0.1297$ \\
C. NICU Stay $>$ 3 Days & $6(21.4)$ & $12(10.71)$ & $\mathrm{p}=0.858$ \\
$\begin{array}{l}\text { D. Neonatal Complications (Resp. } \\
\text { Distress/Apnea/Hyperbilirubinemia) }\end{array}$ & $1(3.57)$ & $1(0.89)$ & \\
E. Neonatal Death & & & \\
\hline
\end{tabular}

in COVID positive group $18(64.3 \%)$ out of 28 had csection as compared to $40(35.7 \%)$ out of 112 in COVID negative group. The most common reason for c-section was patients choice in COVID positive group as compared to fetal distress in COVID negative group.

Based on various studies on mode of delivery, neither cesarean section nor vaginal delivery confers any additional risk to either mother or fetus. Vaginal delivery rate was observed to be $57.1 \%$ without any neonatal complications. $^{22}$ Use of Personal protective (PPE) kits, N95 masks, and universal precautions are necessary during both vaginal delivery and c-section. Adherence to Universal precautions is key to containment of COVID infection.

CTG monitoring for asymptomatic patients is not recommended however Continuous CTG monitoring for symptomatic patient in labor with well equipped centre with facility for emergency obstetrics, critical care and neonatal care is necessary for successful maternal and fetal outcome.

For superadded infection patients were given Azithromycin and HCQ in mild cases. Other drugs like remdesivir \& ritonavir were not used in patients in our study as all were mildly symptomatic. ${ }^{23}$ None of the patient required mechanical and prone ventilation as there was no severe or critical case with respiratory complications such as ARDS.Diet was planned by dietician for all pregnant patients and were encouraged mild stretching yoga exercises while sitting and standing.

Research from Riccardo Davanzo et al. has not shown virus in breast milk. ${ }^{24}$ In light of available evidence through case series benefit of breast feeding seems to outweigh any potential risk of transmission of the virus through breast milk. If mother is too sick then neonate can be managed separately and fed freshly expressed breast milk. In our study we encouraged all patients to breast feed.

Our study clearly demonstrated an increased incidence of preterm delivery, small for gestation age and low APGAR in women affected with COVID as compared to unaffected matched population. The strength of our study was well matched comparison between the two groups with comparable baseline characteristics. Most of the studies published in western countries are hampered by small clinical samples. 


\section{Conclusion}

Maternal and perinatal outcome in COVID positive pregnant women depend on the severity of symptoms at presentation. As obstetrician, we should test for COVID in all high risk pregnant women. We should make them aware of the potential obstetric and neonatal outcomes to allay the apprehension about the disease in patients, combined with more intensive monitoring during pregnancy. This study emphasize on the need for regular antenatal and medical follow up and good perinatal care for COVID positive mothers.

\section{Source of Funding}

None.

\section{Conflict of Interest}

The authors declare that there is no conflict of interest.

\section{References}

1. Lauer SA, Grantz KH, Bi Q, Jones FK, Zheng Q, Meredith HR. The Incubation Period of Coronavirus Disease 2019 (COVID-19) From Publicly Reported Confirmed Cases: Estimation and Application. Ann Intern Med. 2020;172(9):577-82. 101:10.7326/m20-0504

2. Fu L, Wang B, Yuan $\mathrm{T}$, Chen $\mathrm{X}$, Ao $\mathrm{Y}$, Fitzpatrick $\mathrm{T}$, et al. Clinical characteristics of coronavirus disease 2019 (COVID-19) in China: A systematic review and meta-analysis. $J$ Infect. 2020; doi:10.1016/1.jinf.2020.03.041].

3. Wong SF, Chow KM, Leung TN. Pregnancy and perinatal outcomes of women with severe acute respiratory syndrome. Am J Obstet Gynecol. 2004;191:292-7.

4. Alfaraj SH, Al-Tawfiq JA, Memish ZA. Middle East Respiratory Syndrome Coronavirus (MERS-CoV) infection during pregnancy: Report of two cases \& review of the literature. J Microbiol, Immunol Infect. 2019;52(3):501-3. 101:10.1016/1.jmi1.2018.04.005.

5. Chen H, Guo J, Wang C, Luo F, Yu X, Zhang W, et al. Clinical characteristics and intrauterine vertical transmission potential of COVID-19 infection in nine pregnant women: a retrospective review

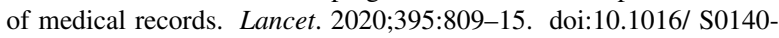
$6736(20) 30360-3$.

6. Yu N, Li W, Kang Q. Clinical features and obstetric and neonatal outcomes of pregnant patients with COVID-19 in Wuhan, China: a retrospective, single-centre, descriptive study. Lancet Infect Dis. 2020;20(5):559-64. do1:10.1016/S1473-3099(20)30176-6.

7. Allam M, Cai S, Ganesh S, Venkatesan M, Doodhwala S, Song Z, et al. COVID-19 Diagnostics, Tools, and Prevention. Diagn. 2020;10:409. do1:10.3390/diagnostics10060409.

8. Center of Disease Control, Interim Guidelines for Collecting, Handling, and Testing Clinical Specimens from Persons under Investigation (PUIs) for Coronavirus Disease 2019 (COVID-19); 2020

9. Yang X, Yu Y, Xu J, Shu H, Xia J, Liu H, et al. Clinical course and outcomes of critically ill patients with SARS-CoV-2 pneumonia in Wuhan, China: a single-centered, retrospective, observational study. Lancet Respir Med. 2020;8(5):475-81.

10. Chan JF, Yip CC, To KK, Tang TH, Wong SC, Leung KH, et al. Improved Molecular Diagnosis of COVID-19 by the Novel, Highly Sensitive and Specific COVID-19-RdRp/Hel RealTime Reverse Transcription-PCR Assay Validated In Vitro and with Clinical Specimens. J Clin Microbiol. 2020;58(5):e00310-20.

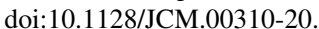

11. FIGO. Safe motherhood and COVID; 2020. Available from: https: //www.figo.org/safe-motherhood-and-covid-19.
12. Dashraath P, Wong JLJ, Lim MXK, Lim LM, Li S, Biswas A. Coronavirus disease 2019 (COVID-19) pandemic and pregnancy. Am J Obstet Gynecol. 2020;222(6):521-31. doi:10.1016/1.ajog.2020.03.021.

13. Chen H, Guo J, Wang C, Luo F, Yu X, Zhang W, et al. Clinical characteristics and intrauterine vertical transmission potential of COVID-19 infection in nine pregnant women: a retrospective review of medical records. Lancet. 2020;395(10226):809-15.

14. Krishnamurthy G, Sahni R, Leone T, Kim F, Brooks MC, VillarazaMorales S, et al. Care of the COVID-19 exposed complex newborn infant. Semin Perinatol. 2020 doi:10.1016/1.semperi.2020.151282

15. Sardu C, Gambardella J, Morelli MB, Wang X, Marfella R, Santulli G, et al. Hypertension, Thrombosis, Kidney Failure, and Diabetes: Is COVID-19 an Endothelial Disease? A Comprehensive Evaluation of Clinical and Basic Evidence. J Clin Med. 2020;9(5):1417. 001:10.3390//cm9051417.

16. Frazer JS, Everden AJT. Emerging patterns of hypercoagulability associated with critical COVID-19: A review. Trends Anaesth Crit Care. 2020;01:10.1016/1.tacc.2020.07.004.

17. RCOG Royal College of Obstetrics and Gynaecology: Coronavirus (covid-19) Infection in Pregnancy. Information for Healthcare Professionals. Version 4 [(accessed on 12 April 2020)].

18. Hantoushzadeh S, Aliabad RA, Norooznezhad AH. Antibiotics, Inflammation, and Preterm Labor: A Missed Conclusion. J Inflamm Res. 2020;13:245-54. doi:10.2147/jir.s248382.

19. Ryan GA, Purandare NC, Mcauliffe FM, Hod M, Purandare CN. Clinical update on COVID-19 in pregnancy: A review article. J Obstet Gynaecol Res. 2020;do1:10.1111/jog.14321.

20. Mcintosh JJ. Corticosteroid Guidance for Pregnancy during COVID19 Pandemic. Am J Perinatol. 2020;37(8):809-12. dor:101055/s0040-1709684.

21. Dubey P, Reddy SY, Manuel S, Dwivedi AK. Maternal and neonatal characteristics and outcomes among COVID-19 infected women: An updated systematic review and meta-analysis. Eur J Obstet Gynecol Reprod Biol. 2020;252:490-501. do1:10.1016/].ejogrb.2020.07.034

22. Boelig RC, Manuck T, Oliver EA, Mascio DD, Saccone G, Bellussi F, et al. Labor and delivery guidance for COVID-19. Am J Obstet Gynecol MFM. 2020;2(2). [oi:10.1016/j.ajogmf.2020.100110.

23. Das S, Bhowmick S, Tiwari S, Sen S. An Updated Systematic Review of the Therapeutic Role of Hydroxychloroquine in Coronavirus Disease-19 (COVID-19). Clin Drug Investig. 2020;40(7):591-601.

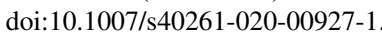

24. Martins-Filho PR, Santos VS, Santos HP. To breastfeed or not to breastfeed? Lack of evidence on the presence of SARS-CoV-2 in breastmilk of pregnant women with COVID-19. Rev Panam Salud Publica. 2020;44. ब01:10.26633/rpsp.2020.59

\section{Author biography}

Vikas Yadav, Assistant Professor

Neerja Goel, Professor

Naima Afreen, Assistant Professor

Nimmi Chutani, Professor and HOD

Shelly Agarwal, Associate Professor

Archana Mehta, Professor

Cite this article: Yadav V, Goel N, Afreen N, Chutani N, Agarwal S,

Mehta A. COVID 19 in pregnancy; obstetrical and neonatal outcomes: A retrospective comparative study. Indian J Obstet Gynecol Res 2020;7(4):584-589. 